\section{USDA, ARS Beit Alpha Cucumber Inbred Backcross Line Population}

\author{
Jack E. Staub ${ }^{1,3,4}$ and Isabelle Y. Delannay ${ }^{2}$ \\ Vegetable Crops Research, U.S. Department of Agriculture, Agricultural \\ Research Service, Department of Horticulture, University of Wisconsin, \\ Madison, WI 53706
}

Additional index words. Cucumis sativus, genetic distance, vegetable breeding

Beit Alpha cucumber (Cucumis sativus L.) is a Mediterranean fresh-market or processed type that originated in Israel for use in openfield and protected production (Shaw et al., 2000; Villalta et al., 2003). This market type develops moderately small ( 15 to $18 \mathrm{~cm}$ in length), slightly curved, uniform green, fruit with fine, and white spines without ridges, which is economically important in many Mediterranean production areas and has potential for protected production in the United States (Hochmuth et al., 2004; Shaw et al., 2007; Villalta et al., 2003). The cultivation of Beit Alpha cucumber is relatively recent, and this market type originated as a selection from a local landrace. Selection was reportedly initiated around 1950 on the Beit Alpha (synonym Beit Alfa or Bet Alfa) Kibbutz (a collective agrarian community) found in northern Israel near the Gilboa ridge (Davidi, 2009; Shaw et al., 2004). The initial breeding on this market type eventually produced a monoecious uniform variety for open-field production (Davidi, 2009). Public research on this market class in the United States has focused on best management practices to maximize its production (Shaw et al., 2000, 2004, 2007) and Israeli breeding efforts [public and private (Hazera Seeds)] that have yielded such varieties as 'Delilah' (Davidi, 2009). Using Japanese, Indian, Chinese, Dutch, and American germplasm, more mod-

Received for publication 7 Mar. 2011. Accepted for publication 10 Aug. 2011.

The creation of the germplasm described here was funded by Nunhems Vegetable Seeds, De Ruiter Zonen Seeds, Nickerson-Zwann BV, and Enza Zaden Research and Development BV, Haelen, Bergschenhoek, Made, and Enkuizen, The Netherlands, respectively. These IBL and associated markers are now being used by these companies to create improved Beit Alpha type germplasm.

Mention of a trade name, proprietary product, or specific equipment does not constitute a guarantee or warranty by the USDA and does not imply its approval to the exclusion of other products that may be suitable.

${ }^{1}$ Former Research Horticulturist and Professor.

${ }^{2}$ Former Graduate Student.

${ }^{3}$ Currently at the U.S. Department of Agriculture, Agricultural Research Service, Forage and Range Research Laboratory, Utah State University, Logan, UT 84322-6300.

${ }^{4}$ To whom reprint requests should be addressed; e-mail jack.staub@ars.usda.gov. ern commercial varieties possess resistances to viruses and downy mildew.

Based on DNA polymorphisms, the genetic base of cucumber is extremely narrow $\{3 \%$ to $8 \%$ among elite and exotic germplasm and $12 \%$ between botanical varieties $[C$. sativus var. sativus L. and var. hardwickii (R.) Alef.]\} (Dijkhuizen et al., 1996; Horejsi and Staub, 1999). The genetic base of several cucumber market types has been estimated using various molecular markers, and the genetic distance (GD) among Mediterranean-types (including the Beit Alpha type) is considered relatively broad (GD $=0.09-0.55)$ when compared with other cucumber market classes such as the European Long type (GD $=0.00$ 0.24) (Dijkhuizen et al., 1996). Although genetic information regarding Beit Alpha types is limited (Hochmuth et al., 2004; Soleimani et al., 2009), Beit Alpha market type germplasm has potential as source material for U.S. breeding programs that develop cultivars for protected (gynoecious, mutiple pistillate, parthenocarpic) and open-field production (vegetative vigor, shortened days to anthesis, multiple lateral branching) environments (Sun et al., 2006).

Dutch and Israeli seed companies have conducted intensive breeding of Beit Alpha cucumber. However, there are few public institutions directing efforts toward reporting the genetics and diversity of Beit Alpha germplasm, and none have provided highly inbred, genetically diverse germplasm for unfettered use in public breeding programs. Because of the lack of genetic information, insufficient publicly released germplasm, and its recent, single source origin (Israel), the genetic base of Beit Alpha cucumber germplasm should be diversified to maximize its use in plant improvement. The inbred backcross breeding method (Wehrhahn and Allard, 1965) has been useful for broadening the genetic base of cucumber and providing novel populations for genetic analysis of complex traits (Owens et al., 1985a, 1985b). This breeding method, when used in conjunction with marker-assisted selection (MAS) for maximum genetic diversity, can provide an array of homozygous lines that are heterogeneous with large percentages of the recurrent parent genotype $(\approx 87 \%)$. Therefore, a series of Beit Alpha inbred backcross lines $\left(\mathrm{BC}_{2} \mathrm{~S}_{3}\right.$; IBL) were developed through MAS and phenotypic selection and released in January 2011 by the Agricultural Research Service, U.S. Department of
Agriculture through its web-based documentation system (ARIS). Markers used in MAS were single sequence repeats (SSR), sequence characterized amplified regions (SCAR), and single nucleotide polymorphisms (SNP), in which their complete description is given in Delannay (2009) and Delannay and Staub (2010). This is the first public release of genetically diverse but highly inbred Beit Alpha germplasm. The IBL were made available to cucumber breeders to supply a source from which they may develop Beit Alpha market types with increased genetic diversity and yield potential suitable for open-field and greenhouse production. These IBL have use for the genetic analysis of complex traits (e.g., yield and quality components) that are common to most cucumber improvement programs (e.g., characterization of epistatic interactions; Robbins et al., 2008; Tanksley et al., 1996).

\section{Origin}

The 117 IBL were developed by crossing Beit Alpha line '04HD5' (De Ruiter Seeds, The Netherlands; recurrent parent) and PI 285606 (Poland; donor parent; European processing type) and then selecting the most genetically diverse $\mathrm{BC}_{1}$ (51 individuals) and $\mathrm{BC}_{2}$ progeny (120 individuals) based on molecular marker profiles (Delannay, 2009) followed by three generations of single-seed descent $\left(\mathrm{BC}_{2} \mathrm{~S}_{3}\right)$ (Tanksley et al., 1996; Wehrhahn and Allard, 1965). Three IBL were eliminated by poor seed production.

The parents ('04HD5' and PI 285606) used for IBL development were selected from 42 accessions [20 elite cucumber lines, 17 diverse PIs from the U.S. National Plant Germplasm System (NPGS) (Horejsi and Staub, 1999)] and five breeding lines from the U.S. Department of Agriculture, Agricultural Research Service (USDA, ARS) cucumber breeding project, Madison, WI, based on their genetic diversity (Delannay, 2009; Delannay and Staub, 2010). The standard cucumber marker array developed by Horejsi and Staub (1999; 44 mapped and 27 unmapped random amplified polymorphic DNA markers) was used to provide an initial estimate of GD for use in a multivariate analysis [Principle Components Analysis (PCA)] to identity highly diverse parental lines (Delannay and Staub, 2010).

Gynoecious line 04HD5 (backcross recurrent parent) is an elite Beit Alpha type inbred line obtained from De Ruiter Seeds (Bergschenhoek, The Netherlands) that typically possesses several (two to three) pistillate flowers per node (multipistillate) depending on growing environment (Delannay, 2009). The monoecious landrace PI 285606 (backcross donor parent) originates from Warsaw, Poland, and was obtained by the U.S. NPGS in 1963. Line 04 HD5 flowers $\approx 1$ week later than PI 285606 and produces fruits (approximate length $=15 \mathrm{~cm}$ ) that are slightly longer than those of PI 285606 (approximate length = $12 \mathrm{~cm}$ ) (Delannay, 2009; Delannay and Staub, 2010). Although smooth (without predominant ridges), fine-spined (white in color) fruits of line 
04HD5 remain green beyond optimal commercial maturity (over-sized fruit), PI 285606 fruit have thick, black-spines and turn orange on maturity. Their $F_{1}$ progeny are predominantly female and develop fruit with thin, black spines. The IBL developed from the $F_{1}$ progeny differ in these and other (e.g., vegetative vigor, lateral branching; Table 1) economically important traits (Shaw et al., 2007).
The development of $\mathrm{BC}_{2} \mathrm{~S}_{3}$ IBL was initiated by the selection of the most genetically diverse $\mathrm{BC}_{1}$ progeny (51 of $392 ; 13 \%$ selection intensity) based on 46 [including 24 mapped SSR (nine), SCAR (eight), and SNP (seven)] marker profiles that define their heterozygosity (Delannay and Staub, 2010). These $\mathrm{BC}_{1}$ individuals were crossed to the cloned recurrent parent to produce $\mathrm{BC}_{2}$ progeny and then approximately eight seeds from each of the $\mathrm{BC}_{2}$ families (384 total seeds) were planted, sampled for DNA at the third-leaf stage, and greenhousegrown for pollination. One hundred twenty $\mathrm{BC}_{2}$ individuals having the greatest heterozygosity as defined by molecular genotyping were selfpollinated to produce $\mathrm{BC}_{2} \mathrm{~S}_{3}$ lines.

Molecular genotyping of $\mathrm{BC}_{2} \mathrm{~S}_{3}$ IBL was performed, and IBL were evaluated $(22,200$

Table 1. Combined four location (USA, The Netherlands, Israel, and Turkey) trait means and sEs of parents (04HD5 and PI 285606) and their derived cucumber (Cucumis sativus L.) inbred backcross lines $\left(117 \mathrm{BC}_{2} \mathrm{~S}_{3}\right)$ taken collectively (combined IBL) or as groups (as framed by multivariate analysis) as evaluated in 2008 .

\begin{tabular}{|c|c|c|c|c|c|c|c|c|}
\hline \multirow[b]{2}{*}{ Trait $^{\mathrm{z}}$} & \multicolumn{4}{|c|}{$04 \mathrm{HD}^{\mathrm{y}}$} & \multicolumn{4}{|c|}{ PI $285606^{\mathrm{x}}$} \\
\hline & Mean $^{q}$ & SE & Minimum & Maximum & Mean & SE & Minimum & Maximum \\
\hline Days to anthesis & 29.05 & 7.18 & 20.00 & 41.00 & 20.56 & 4.57 & 16.00 & 31.00 \\
\hline Percent gynoecious & 94.44 & 12.78 & 66.67 & 100.00 & 10.00 & 28.87 & 0.00 & 100.00 \\
\hline Pistillate flowers per node & 2.11 & 0.68 & 1.00 & 4.00 & 1.08 & 0.49 & 0.00 & 2.00 \\
\hline Lateral branch number & 2.67 & 1.68 & 0.00 & 6.00 & 2.72 & 1.28 & 0.00 & 5.00 \\
\hline Fruit yield & 0.60 & 0.79 & 0.00 & 1.67 & 0.11 & 0.16 & 0.00 & 0.33 \\
\hline Fruit length $(\mathrm{cm})$ & 13.43 & 2.91 & 9.31 & 16.76 & 11.10 & 1.91 & 6.35 & 12.83 \\
\hline Fruit weight (g) & 94.49 & 33.20 & 50.00 & 170.59 & 128.62 & 49.40 & 42.00 & 190.00 \\
\hline \multirow[t]{2}{*}{ Genetic distance } & 0.41 & 0.16 & 0.00 & 0.85 & 0.72 & 0.08 & 0.39 & 0.85 \\
\hline & \multicolumn{4}{|c|}{ Combined IBL ${ }^{\mathrm{w}}$} & \multicolumn{4}{|c|}{ Group $1 \mathrm{IBL}^{\mathrm{v}}$} \\
\hline Trait $^{z}$ & Mean & $\mathrm{SE}$ & Minimum & Maximum & Mean & SE & Minimum & Maximum \\
\hline Days to anthesis & 20.41 & 5.81 & 11.00 & 42.00 & 22.03 & 5.77 & 12.00 & 37.00 \\
\hline Percent gynoecious & 80.56 & 28.89 & 33.33 & 100.00 & 50.92 & 28.04 & 33.33 & 100.00 \\
\hline Pistillate flowers per node & 2.06 & 1.18 & 0.00 & 8.00 & 1.33 & 0.94 & 0.00 & 5.00 \\
\hline Lateral branch number & 4.72 & 3.56 & 0.00 & 7.60 & 5.24 & 3.28 & 0.00 & 15.00 \\
\hline Fruit yield & 6.01 & 3.50 & 0.00 & 20.00 & 4.04 & 3.60 & 0.00 & 17.00 \\
\hline Fruit length $(\mathrm{cm})$ & 13.69 & 2.32 & 0.00 & 23.37 & 17.08 & 2.41 & 12.00 & 23.37 \\
\hline Fruit weight (g) & 111.59 & 50.82 & 0.00 & 500.00 & 149.63 & 78.77 & 50.00 & 500.00 \\
\hline \multirow[t]{2}{*}{ Genetic distance } & 0.48 & 0.13 & 0.00 & 0.85 & 0.51 & 0.09 & 0.27 & 0.59 \\
\hline & \multicolumn{4}{|c|}{ Group $2 \mathrm{IBL}^{\mathrm{u}}$} & \multicolumn{4}{|c|}{ Group $3 \mathrm{IBL}^{\mathrm{t}}$} \\
\hline Trait $^{z}$ & Mean & SE & Minimum & Maximum & Mean & SE & Minimum & Maximum \\
\hline Days to anthesis & 20.83 & 5.12 & 12.00 & 35.00 & 18.13 & 4.36 & 12.00 & 35.00 \\
\hline Percent gynoecious & 98.54 & 8.92 & 33.33 & 100.00 & 99.47 & 4.17 & 66.67 & 100.00 \\
\hline Pistillate flowers per node & 2.08 & 1.08 & 1.00 & 6.00 & 2.72 & 1.17 & 1.00 & 7.00 \\
\hline Lateral branch number & 6.13 & 3.88 & 0.00 & 17.00 & 4.97 & 3.17 & 0.00 & 13.00 \\
\hline Fruit yield & 6.95 & 3.99 & 0.00 & 20.00 & 9.56 & 4.63 & 1.67 & 20.00 \\
\hline Fruit length $(\mathrm{cm})$ & 15.17 & 2.21 & 9.50 & 22.00 & 13.44 & 1.64 & 9.74 & 17.78 \\
\hline Fruit weight (g) & 129.79 & 53.88 & 33.33 & 290.00 & 111.30 & 51.24 & 30.67 & 380.00 \\
\hline \multirow[t]{2}{*}{ Genetic distance } & 0.55 & 0.22 & 0.27 & 0.84 & 0.36 & 0.11 & 0.09 & 0.59 \\
\hline & \multicolumn{4}{|c|}{ Group $4 \mathrm{IBL}^{\mathrm{s}}$} & \multicolumn{4}{|c|}{ Group $5 \mathrm{IBL}^{\mathrm{r}}$} \\
\hline Trait $^{z}$ & Mean & SE & Minimum & Maximum & Mean & SE & Minimum & Maximum \\
\hline Days to anthesis & 19.83 & 4.90 & 11.00 & 37.00 & 22.00 & 6.45 & 12.00 & 40.00 \\
\hline Percent gynoecious & 97.51 & 9.95 & 33.33 & 100.00 & 68.02 & 32.90 & 33.33 & 100.00 \\
\hline Pistillate flowers per node & 2.78 & 1.26 & 1.00 & 7.00 & 1.43 & 0.90 & 0.00 & 4.00 \\
\hline Lateral branch number & 3.77 & 3.07 & 0.00 & 15.00 & 4.00 & 3.15 & 0.00 & 15.00 \\
\hline Fruit yield & 6.92 & 3.40 & 0.25 & 16.00 & 3.99 & 3.38 & 0.00 & 13.00 \\
\hline Fruit length $(\mathrm{cm})$ & 12.25 & 1.78 & 7.11 & 16.64 & 12.80 & 2.26 & 7.62 & 17.53 \\
\hline Fruit weight (g) & 95.68 & 40.32 & 18.00 & 260.00 & 97.74 & 43.55 & 17.00 & 233.33 \\
\hline Genetic distance & 0.40 & 0.16 & 0.00 & 0.72 & 0.50 & 0.07 & 0.34 & 0.60 \\
\hline
\end{tabular}

${ }^{\mathrm{z}}$ Days to anthesis was recorded as the number of days between transplanting and the appearance of the first fully expanded corolla averaged by group; Percent gynoecious was recorded as the percent of gynoecious plants per group; Pistillate flowers per node was recorded as the maximum number of pistillate flowers found per node averaged by group; Lateral branch number was recorded as the average number of lateral branches on the first ten nodes; Fruit yield was recorded as the average cumulative fruit yield per plant for each group over 3 harvests; Fruit length was the average length of a commercially mature fruit over three harvests; Fruit weight was the average weight of a single fruit per plot over three harvests; Genetic distance was calculated as the average genetic distance using Rogers (1972) genetic distance formula as modified by Wright (1978) comparing all lines with that of lines within the given group.

y04HD5 is a inbred Beit Alpha line from De Ruiter Seeds, The Netherlands.

xPI 285606 is a PI originating from Warsaw, Poland.

${ }^{\mathrm{w}}$ Combined IBL contains all 117 inbred backcross lines $\left(\mathrm{BC}_{2} \mathrm{~S}_{3}\right)$ developed by crossing 04HD5 (recurrent parent) with PI 285606 (donor parent), backcrossing twice by marker-assisted selection for maximum heterozygosity, and then self-pollinating three times.

${ }^{v}$ Group 1 IBL is a subset grouping identified as distinct and consists of IBL 56, 62, 136, and 160.

${ }^{u}$ Group 2 IBL is a subset grouping identified as distinct and consists of IBL 29, 58, 77, 112, and 162.

${ }^{t}$ Group 3 IBL is a subset grouping identified as distinct and consists of IBL 60, 86, 90, 118, 124 , and 142.

${ }^{s}$ Group 4 IBL is a subset grouping identified as distinct and consists of IBL 1, 3, 10, 26, 38, 87, 100, 111, 139 , and 151.

${ }^{\mathrm{r}}$ Group 5 IBL is a subset grouping identified as distinct and consists of IBL 17, 74, 94, 121, 143, and 152.

${ }^{\mathrm{q}}$ Mean, sDs, minimum, and maximum values for each population within a trait.

$\mathrm{IBL}=$ inbred backcross lines. 
plants/ha) in replicated trials for days to anthesis, sex expression (SE), pistillate flowers per node (PFN), lateral branch number (LBN), fruits per plant (FN), fruit length (FL), and fruit weight (FW) in the United States (Hancock, WI; open field), Enkhuizen, The Netherlands; Beit Hanan, Israel; and Antalya, Turkey ("hoop houses") (Delannay, 2009; Delannay and Staub, 2010). Average FN and fruit size characteristics are presented here on a perplant basis because these characteristics and their market value can vary with harvest interval (Staub et al., 2008). The growing conditions at each test location varied dramatically (Delannay, 2009; Delannay and Staub, 2010).

The intent of the backcrossing with MAS was to provide lines that possessed Beit Alpha market type characteristics, which varied in economically important traits (e.g., fruit length and weight, days to anthesis). Genotypic data and phenotypic data specific to each location and for each IBL can be found in Delannay (2009) and Delannay and Staub (2010). This phenotypic and genotypic assessment allowed for rigorous characterization of IBL for future use of the IBL for breeding, MAS, and genetic analysis.

\section{Description}

Analysis of variance and multivariate analysis (PCA) of phenotypic and genotypic data led to a characterization of IBL and allowed for comparative analyses (Delannay, 2009; Delannay and Staub, 2010). Location and lines were treated as fixed effects and block was treated as a random effect, and homogeneity of trait variances were evaluated by Bartlett's test (Delannay, 2009). Location differences were detected to a greater or lesser extent for all traits. However, generally, the rankings of lines across locations for all traits examined were similar and, thus, they were combined for presentation here.

Principle components (PC) 1, 2, and 3 after PCA of phenotypic data taken collectively over all locations accounted for $36.5 \%, 20.3 \%$, and $15.3 \%$ of the observed phenotypic variation, respectively (total $=72.1 \%$ ) (Delannay, 2009; Delannay and Staub, 2010). Traits important in explaining phenotypic variation among IBL were: PFN, SE, and FN (PC1); FL and FW (PC 2); and LBN and FN (PC 3). The most diverse IBL (identified by graphical appraisal after PCA) could be separated into five phenotypically distinct groups (Groups 1-5) that differed from a major central grouping (Group 6). Group 1 contained IBL $56,62,136$, and 160; Group 2 consisted of IBL 29, 58, 77, 112, and 162; Group 3 included IBL $60,86,90,118,124$, and 142; Group 4 included IBL 1, 3, 10, 26, 38, 87, 100, 111, 139, and 151; and Group 5 consisted of IBL 17, 74, 94, 121, 143, and 152 (Table 1).

Multivariate analyses using Rogers GDs defined genotypic relationships among and between the six groupings (Delannay, 2009; Delannay and Staub, 2010). As might be predicted, the parental lines (PI 285606 and 04HD5) were most distinct genetically
$(\mathrm{GD}=0.90)$. Although IBL, in the main, were more closely related to parental line 04HD5 (average GD $=0.41$ ) than to PI 285606 (average GD =0.72), IBL 29 was most distant from line 04HD5 $(\mathrm{GD}=0.72)$.

Line '04HD5' and PI 285606 are genotypically and phenotypically distinct (Delannay, 2009; Delannay and Staub, 2010). Through backcross MAS, these parental lines led to the development of IBL that have potential for use in traditional and MAS breeding to maximize genetic diversity and breeding potential in Beit Alpha germplasm (Behera et al., 2011; Fan et al., 2006; Robbins and Staub, 2009) and for the genetic analysis of traits (e.g., identification of epistasis for the effective pyramiding of quantitative trait loci; Robbins et al., 2008; Tanksley et al., 1996). Knowledge of the phenotypic differences and relative GDs between IBL is critical for the realization of each of these goals. All IBL develop fruit with standard Beit Alpha characteristics (i.e., uniform green, fine spines, non-rigged) but vary in size and hue. For instance, Group 1 IBL are notably longer than the parents from which they are derived (Table 1). Fruit length in cucumber is controlled by relatively few genes (3-5 depending on population), which are epistatic to each other (Fazio et al., 2003), and their allelic alignment in Group 1 may provide a partial explanation for their unusually long fruit length (Robbins et al., 2008). Specific maximum and minimum GD detected between IBL was 0.86 and 0.0 , respectively (Delannay, 2009; Delannay and Staub, 2010). Although the maximum GD detected (0.86) between entries occurred between phenotypically distinct IBL 3 and 29 , the GD between IBL 60 and 111 was zero. Because no map exists for the Beit Alpha market type, these IBL have use as parents for map construction [i.e., IBL 3 (gynoecious, multipistillate, high yield, and small, lightcolored fruit) $\times$ IBL 29 (monoecious, few multipistillate nodes, low yield, large, darkcolored fruit)] and genetic trait analysis (Fazio et al., 2003; Robbins et al., 2008).

The diverse set of IBL being released have been genetically characterized and, thus, can be used directly for introgression backcrossing to create germplasm customized for particular open-field and protected environment growing conditions (Delannay, 2009; Delannay and Staub, 2010). For instance, Group 1 contains IBL that produce fruit that are comparatively long $(17.0 \mathrm{~cm})$ but are mainly monoecious and have relatively low yield (4.0 fruits/plant) and low PFN (1.3 pistillate flowers/node) (Table 1; Delannay, 2009; Delannay and Staub, 2010). In contrast, the performance of Group 2 and Group 3 IBL are nearly average for all traits, except that several Group 2 lines develop more lateral branches (6.1). All of Group 3 IBL are strongly gynoecious and bear many PFN (multipistillate; 2.7), and some are comparatively high-yielding (up to 20 fruits/plant). The fact that these IBL develop fruit that are medial in length (13.4 cm) and weight (111.3 g) makes them immediately attractive for use in the development of base populations for plant improvement. In contrast, Group 4 IBL are typically gynoecious and possess an above-average number of PFN (2.8), but their yield is only average (6.9 fruits/plant and $95.7 \mathrm{~g} /$ fruit) and they tend to possess only an average number lateral branches (3.8). Likewise, Group 5 IBL are mostly monoecious, bear relatively few PFN (1.4) and lateral branches (4.0), and are comparatively lowyielding (4.0 fruits/plant and $97.7 \mathrm{~g}$ /fruit). After initial evaluation of these IBL in specific target environments (open-field, protected environments), strategic crossing of selected IBL with fully characterized (i.e., genomic analysis) elite lines may allow for the development of broad- and narrow-based populations for recurrent selection or for more directed selection (MAS and/or phenotypic selection) during backcrossing (Fan et al., 2006). The markers used to define these IBL can be used to assess genetic diversity (i.e., GD values) during germplasm development through MAS. Furthermore, many economically important traits are controlled by relatively few genes (sex expression, disease resistance) in cucumber (Staub et al., 2008). Given the variability detected in the IBL described here and the short life cycle of cucumber (3-4 months), it will be relatively easy to incorporate those traits controlled by a few genes in progeny derived from IBL (e.g., IBL $\times$ elite commercial germplasm).

\section{Availability}

Seed of 117 Beit Alpha IBL representing the six groups identified after PCA [Group 1= $4 \mathrm{IBL}$, Group $2=5 \mathrm{IBL}$, Group $3=6 \mathrm{IBL}$, Group $4=10$ IBL, Group $5=6$ IBL, and Group $6($ central $)=86$ IBL] from a hand-pollinated greenhouse increase may be obtained by addressing requests to P.W. Simon, Vegetable Crops Research, U.S. Department of Agriculture, Agricultural Research Service, Department of Horticulture, University of Wisconsin, Madison, WI 53706. A customized request can be made of any or all of the IBL based on the phenotypic and genotypic data presented here and in Delannay and Staub (2010). Genotyped IBL can be evaluated for introgression of useful traits into elite germplasm, and for mapping traits, analysis of quantitative trait loci and epistatic interactions.

\section{Literature Cited}

Behera, T.K., J.E. Staub, I.Y. Delannay, and J.F. Chen. 2011. Marker-assisted backcross selection in an interspecific Cucumis population broadens the genetic base of cucumber ( $\mathrm{Cucu}$ mis sativus L.). Euphytica 178:261-272.

Davidi, H. 2009. A historical survey of cucumber breeding in Israel. Proceedings of the IV Balkan Symposium on Vegetables and Potatoes. ISHS Acta Horiticulturae 830, Vol. 1. p. 33-36.

Delannay, I.Y. 2009. Use of molecular markers to increase genetic diversity of Beit Alpha, European Long, and U.S. Processing market classes of cucumber (Cucumis sativus L.) through marker-assisted selection. Ph.D. diss., University of Wisconsin at Madison.

Delannay, I.Y. and J.E. Staub. 2010. Use of molecular markers aids in the development of diverse inbred backcross lines in Beit Alpha 
cucumber (Cucumis sativus L.). Euphytica 175: 65-78.

Dijkhuizen, A., W.C. Kennard, M.J. Havey, and J.E. Staub. 1996. RFLP variation and genetic relationships in cultivated cucumber. Euphytica 90:79-87.

Fan, Z., M.D. Robbins, and J.E. Staub. 2006. Population development by phenotypic selection with subsequent marker-assisted selection for line extraction in cucumber (Cucumis sativus L.). Theor. Appl. Genet. 112:843-855.

Fazio, G., J.E. Staub, and M.R. Stevens. 2003. Genetic mapping and QTL analysis of horticultural traits in cucumber (Cucumis sativus L.) using recombinant inbred lines. Theor. Appl. Genet. 107:864-874.

Hochmuth, R.C., L.L. Davis, W.L. Laughlin, E.H. Simonne, S.A. Sargent, and A. Berry. 2004. Evaluation of twelve greenhouse mini cucumber (Beit Alpha) cultivars and two growing systems during the 2002-2003 winter season in Florida. North Florida Res. \& Educ. Ctr., University of Florida Research-Suwanne Valley. Rpt. 2003-2004:12.

Horejsi, T. and J.E. Staub. 1999. Genetic variation in cucumber (Cucumis sativus L.) as assessed by random amplified polymorphic DNA. Genet. Resources Crop Evol. 46:337-350.

Owens, K.W., F.A. Bliss, and C.E. Peterson. 1985a. Genetic analysis of fruit length and weight in two cucumber populations using the inbred backcross line method. J. Amer. Soc. Hort Sci. 110:431-436.

Owens, K.W., F.A. Bliss, and C.E. Peterson. 1985 b. Genetic variation within and between two cucumber populations derived via the inbred backcross line method. J. Amer. Soc. Hort. Sci. 110:437-441.

Robbins, M.D., M. Casler, and J.E. Staub. 2008. Pyramiding QTL for multiple lateral branching in cucumber using inbred backcross lines. Mol. Breed. 22:131-139.

Robbins, M.D. and J.E. Staub. 2009. Comparative analysis of marker-assisted and phenotypic selection for yield components in cucumber. Theor. Appl. Genet. 119:621-634.

Rogers, J.S. 1972. Measures of genetic similarity and genetic distance. Studies in genetics VII. Univ. Texas Publ. 7213:145-153.

Shaw, N.L., D.J. Cantliffe, J. Funes, and C. Shine. 2004. Successful Beit Alpha cucumber production in the greenhouse using pine bark as an alternative soilless media. HortTechnology 14:289-294.

Shaw, N.L., D.J. Cantliffe, S.T. Rodriguez, and D.M. Spencer. 2000. Beit Alpha cucumber: An exciting new greenhouse crop. Proc. Fla. State Hort. Soc. 113:247-253.

Shaw, N.L., D.J. Cantliffe, and P.J. Stoffella. 2007. A new crop for North American greenhouse growers: Beit Alpha cucumber: Progress of production technology through university research trials. Acta Hort. 731:251-255.
Soleimani, A., A. Ahmadikhah, and S. Soleimani. 2009. Performance of different greenhouse cucumber cultivars (Cucumis sativus L.) in southern Iran. Afr. J. Biotechnol. 8:40774083.

Staub, J.E., M.D. Robbins, and T.C. Wehner. 2008 Cucumber, p. 241-282. In: Prohens, J. and F. Nuez (eds.). Vegetables I: Asteraceae, Brassicaceae, Chenopodiaceae, and Cucurbitaceae. Springer, New York, NY.

Sun, Z., R.L. Lower, and J.E. Staub. 2006. Analysis of generation means and components of variance for parthenocarpy in cucumber (Cucumis sativus L.). Plt. Breed. 125:277-280.

Tanksley, S.D., S. Grandillo, T.M. Fulton, D. Zamir, Y. Eshed, V. Petiard, J. Lopez, and T. Beck-Bunn. 1996. Advanced backcross QTL analysis in a cross between an elite processing line of tomato and its wild relative L. pimpinellifolium. Theor. Appl. Genet. 92:213-224.

Villalta, A.M., S.A. Sargent, A.D. Berry, and D.J. Huber. 2003. Sensitivity of Beit Alpha cucumber (Cucumis sativus L.) to low temperature storage. Proc. Fla. State Hort. Soc. 116:364-366.

Wehrhahn, C. and R.H. Allard. 1965. The detection and measurement of the effects of individual genes involved in the inheritance of a quantitative character in wheat. Genetics 51:109-119.

Wright, S. 1978. Evolution and the genetics of populations. Variability within and among natural populations. U. Chicago Press, Chicago, IL. 